\title{
Benefits of membership
}

\author{
Richard N Fedorak MD \\ President, Canadian Association of Gastroenterology, Edmonton, Alberta
}

$\mathrm{T}$ his is my last President's Page during my tenure as President of the Canadian Association of Gastroenterology (CAG). By the time you read this page, the gavel will have been passed at our Annual Meeting to Dr John Wallace, University of Calgary.

During my 10-year association with the CAG, I have seen it grow from a small colloquial group of 100 members to a vibrant, multifaceted organization of over 600 members, expecting and receiving a diverse array of membership benefits.

\section{CANADIAN DIGESTIVE DISEASES WEEK}

The most visible benefit of membership in the CAG is the Canadian Digestive Diseases Week (CDDW) Annual Meeting, which showcases Canadian digestive sciences, features world renowned experts for 'state of the art' presentation and provides continuing professional education through workshops and satellite symposia. The cost to the CAG for the annual CDDW is approximately $\$ 800,000$.

Best of CDDW CD-ROM: The Best of CDDW CD-ROM comprises $5 \mathrm{~h}$ of video and audio material selected from among the best lectures and presentations at the CDDW. Best of the CDDW, a $\$ 110,000$ initiative, was funded in part through an unrestricted educational grant from Abbott Canada.

CDDW Abstracts on CD-ROM: This popular program provides an electronic copy of the meeting abstracts and is sponsored by an unrestricted educational grant from Astra Canada.

\section{RESEARCH GRANTS AND FELLOWSHIPS}

With a total value of nearly $\$ 1.5$ million, the grant and fellowship program is a flagship endeavor to train clinicians and scientists of the future.

Studentship: Undergraduate science and medical students are exposed to a career in digestive sciences through the 10 to 15 summer studentships awarded across the country each year.

Fellowship: Fourteen fellowships, co-administered with the Medical Research Council (MRC), are granted each year to Canada's top gastrointestinal trainees. These one- or twoyear fellowships extend the traditional two-year clinical training program to provide a foundation that will enable a successful candidate to develop an academic career.

New Investigator Award: Four New Investigator Awards are provided annually to faculty in their first years of ap-

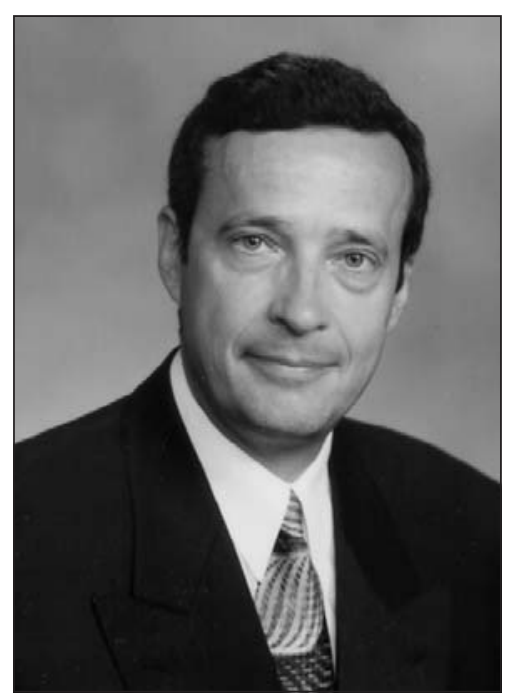

pointment. These awards provide research support during those crucial growth years between fellowship and MRC funding.

Clinical Practice Traineeship: Designed for the practising gastroenterologist who wants an update or to acquire a new skill, the Clinical Practice Traineeship provides partial overhead costs to afford the clinician the time away from his or her practice to meet these objectives.

\section{POSTGRADUATE GASTROINTESTINAL FELLOWS COURSE}

Immediately before the CDDW, 70 of Canada's core gastrointestinal trainees are immersed in an intensive fourday postgraduate course designed to provide an in-depth review of gastroenterology, permit the trainees to present and discuss their own research activities, and, in a relaxed environment, expose them to series of faculty role models. Budgeted at $\$ 120,000$, the Postgraduate Fellows Course is highly rated by trainees and residency program directors.

\section{MOTILITY PROGRAM FOR GASTROINTESTINAL FELLOWS}

Led by the Gastrointestinal Motility Education Centres, this program selects senior core gastrointestinal trainees from each Canadian University, links them with an expert in motility and provides a detailed on-site review course of motility research and education presented at the American 
Digestive Disease Week Meeting. This $\$ 110,000$ program is funded by an unrestricted educational grant from JanssenOrtho Canada.

\section{CAG GASTROINTESTINAL MOTILITY EDUCATION CENTRES}

McMaster University, Queens University and the Université de Montréal comprise the CAG Gastrointestinal Motility Education Centres. This five-year, $\$ 3$ million program, under a grant from Janssen-Ortho Canada, has been given the mandate to advance education of motility disorders at both a primary care and specialist level.

\section{CAG SLIDE KIT BINDERS}

The CAG, in conjunciton with its industrial partners, has developed a series of slide kits to provide a valuable outreach tool. Each binder contains slide lecture kits covering the latest developments for specific gastrointestinal conditions.

\section{CANADIAN SOCIETY OF GASTROINTESTINAL NURSING ASSISTANTS SCHOLARSHIP}

Each year the Endoscopy Committee of the CAG provides up to three $\$ 500$ education awards to members of the Canadian Society of Gastrointestinal Nursing Assistants, enabling them to attend an educational event.

\section{PRACTICE GUIDELINES AND CONSENSUS CONFERENCES}

The clinical practice guidelines $(n=12)$ and consensus conferences $(n=4)$ are a valuable educational component and, when published by The Canadian Journal of Gastroenterology, become an important practical resource for members.

\section{CAG VISITING RESEARCH PROFESSOR PROGRAM}

The CAG Visiting Research Professor is selected annually by the CAG Research Committee. Each year, this individual volunteers his or her time to lecture across Canada. This has been an exciting program that affords provincial gastrointestinal societies, community hospitals and academic centres the opportunity to host a CAG-sponsored research leader.

\section{MEMBER RECOGNITION AWARDS}

Membership is our strength. The CAG honours its members, and prominent gastroenterologists and hepatologists from around the world with a series of distinctions and awards. The Distinguished Service Award, RD McKenna Lecturer, Research Excellence Award and Young Investigator Award provide the CAG with an opportunity to celebrate the achievements of its members.

\section{CAG WEBSITE}

The CAG homepage and website are, without a doubt, CAG's window to the world, with over 25,000 hits per week. With a budget of $\$ 120,000$ annually, the website is currently assessing a series of criteria, including design, executive management, operational issues and its ability to fulfill the association's mission. Within several months, members will be able to access all member benefits via the CAG Website.

\section{RECERTIFICATION PROGRAM}

To meet the Royal College-mandated recertification, the CAG is working to ensure that up to $60 \%$ of annual recertification 'points' can be accrued at the CDDW. Furthermore, through regional educational events, CD-ROMs and direct self-educational links via the CAG website, members will be assured unconstrained opportunity to meet recertification objectives.

\section{THE CANADIAN JOURNAL OF GASTROENTEROLOGY}

The CAG is eternally grateful to Drs Alan Thomson and Noel Williams for their insight in founding The Canadian Journal of Gastroenterology more than 10 years ago. As we move into the next century, the editorial reins have been handed over to Dr Lloyd Sutherland and a new Editorial Board. Within the field of Gastroenterology and Hepatology, there are 44 ranked Journals. The Canadian Journal of Gastroenterology ranks a respectable 30th.

\section{FEDERATED SOCIETIES OF GASTROENTEROLOGY AND HEPATOLOGY}

The federated societies of gastroenterology and hepatology bring together the CAG and the Canadian Association of Study of the Liver into a unified working relationship to ensure that the CDDW and other flagship member benefits are coordinated and effective.

CANADIAN INSTITUTE OF HEALTH RESEARCH The Canadian Institute of Health Research (CIHR) is a new Federal initiative to replace the MRC. During 1999 and 2000, the CAG has been proactive in lobbying for a CIHR in Digestive, Nutritional and Oral Health Sciences. This monumental effort promises to position digestive and nutritional sciences at a level of visibility not previously seen. Hopefully, this effort will translate into a similar level of research and wellness funding.

\section{CANADIAN DIGESTIVE DISEASE FOUNDATION}

The CAG is proud to announce that the Canadian Digestive Disease Foundation (CDDF) has joined as our newest partner for the future. The CDDF is a public foundation with a mandate for research and education in digestive health. As a united fundraising voice, the CDDF and the CAG will work together to advance digestive health through support of research and education.

While the work of the CAG is most visible during the week of the CDDW, it is truly year round and multifaceted. The activities of the CAG are maintained through the work of a small secretariat, and the efforts of numerous volunteers serving on committees and the executive. They work extremely hard on behalf of the membership, and it is a pleasure to thank them for their donation of time and talent to the goals of the CAG. 


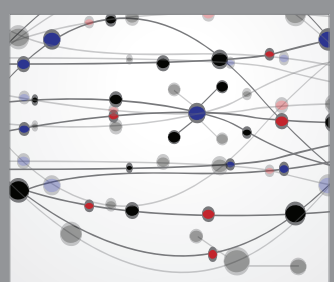

The Scientific World Journal
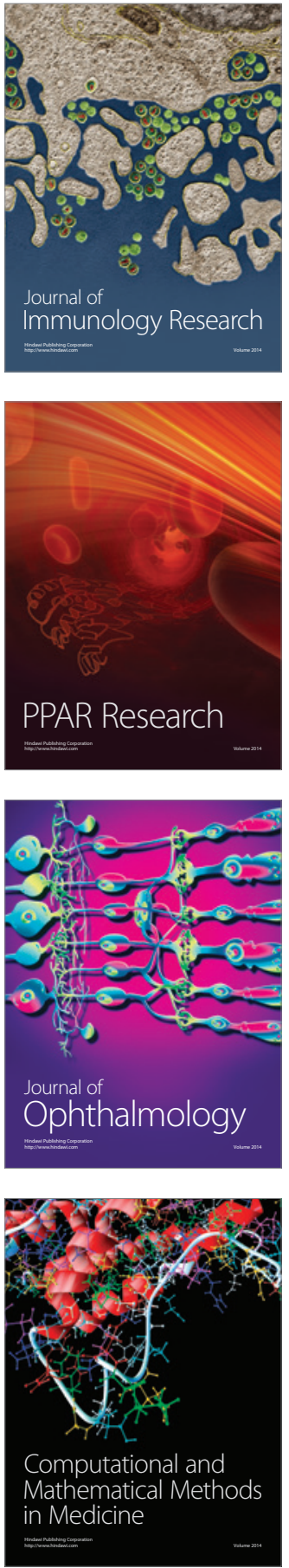

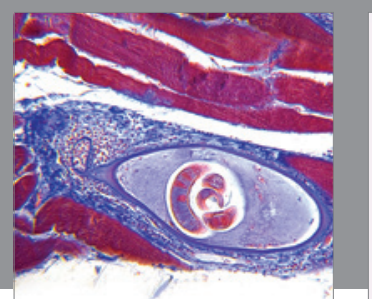

Gastroenterology Research and Practice

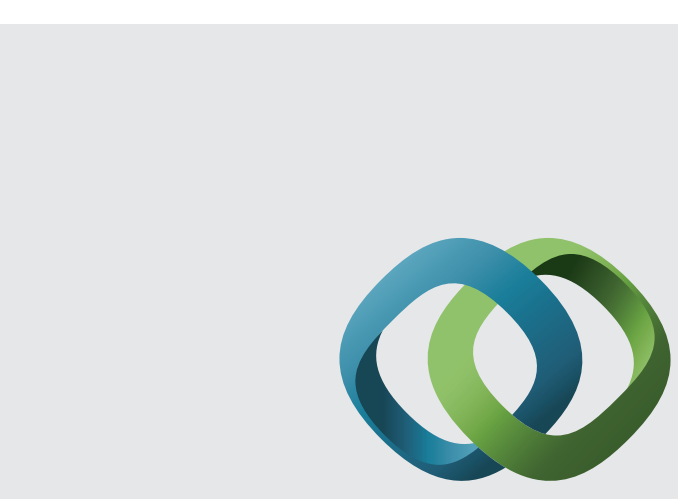

\section{Hindawi}

Submit your manuscripts at

http://www.hindawi.com
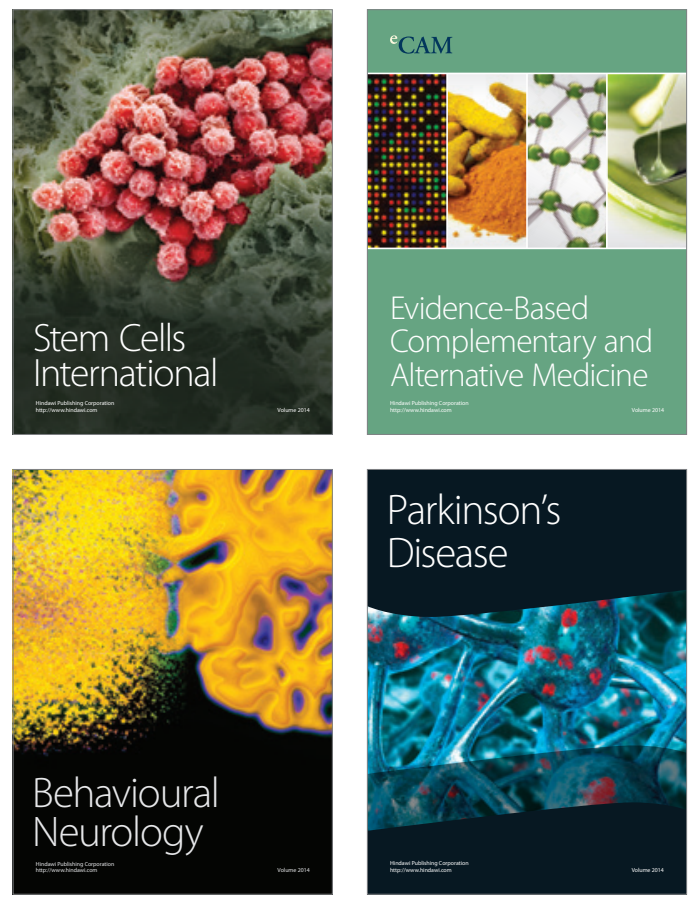
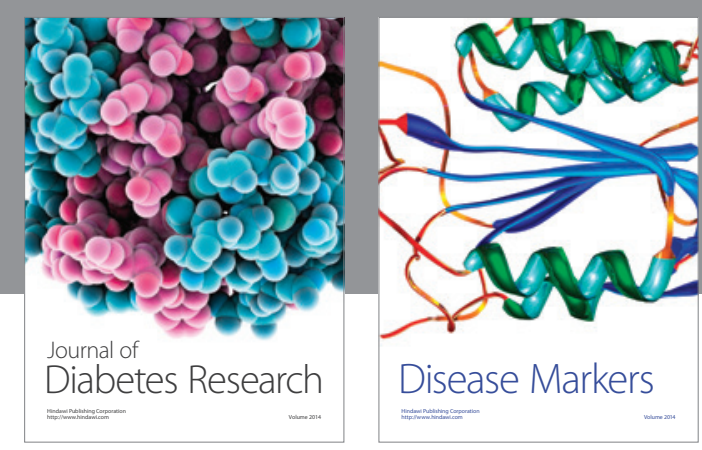

Disease Markers
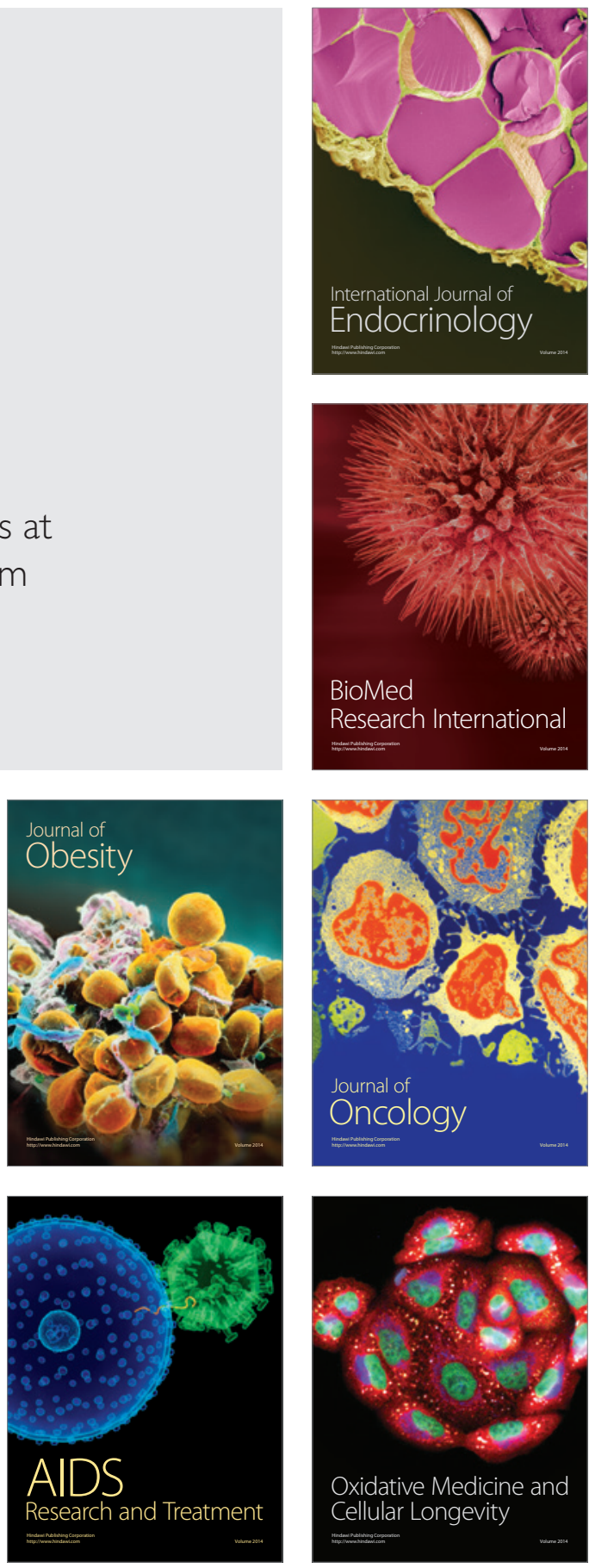